\title{
Research on Packaging Logistics Technology and Logistics Cost Optimization
}

\author{
Gen Cao $^{1}$ Jianxin Chen ${ }^{2}$ \\ 1. Tongji University Shanghai 200092;2. Lenovo Group Shanghai 200092
}

\begin{abstract}
In recent years, the logistics industry has obtained opportunities for development and growth with the continuous development and progress of $\mathrm{e}-$ commerce and the Internet economy. However, many problems have also appeared in logistics cost control with the rapid development of the logistics industry. This not only led to a decline in the economic efficiency of the logistics industry to a certain extent but also had an impact on logistics quality and customer service to a large extent. Due to the important impact of packaging logistics technology on logistics cost management, reasonable research and development and improvement of logistics cost technology can provide a massive boost to logistics cost optimization. The targeted analysis and application of packaging logistics technology can significantly optimize logistics costs and promote the logistics industry and $\mathrm{e}-$ commerce.
\end{abstract}

Keywords: commodity packaging; logistics technology; logistics cost

DOI : $10.36012 /$ ems. v2i2. 2797

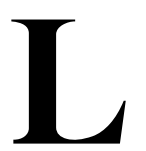

ogistics packaging is an important part of the logistics industry and runs through the entire process of 10gistics activities. It is more reasonable to take packaging logistics technology as an entry point to study the effective control and optimization of lo- $^{-}$ gistics costs. Reasonably improving and perfecting packaging logistics technology is very necessary for the cost control and optimization of logistics enterprises.

1. The importance of optimizing logistics costs by packaging logistics technology

As a comprehensive cross - discipline, packaging logistics technology involves knowledge of packaging, logistics, transportation, and management disciplines, as well as information science and technology. The object of packaging logistics technology research is goods and commodities with substantive material characteristics and the physical movement from the supplier to the demander, creating added value in time, space, and processing. The application of packaging logistics technology is to strengthen the packaging protection of goods and commodities, making it more convenient for storage, transportation, and circulation, ensuring logistics safety, and targeted control of packaging logistics costs to achieve certain environ- 
mental protection and resource regeneration goals ${ }^{[1]}$.

In the logistics costs, the overall logistics packaging costs account for about $36 \%$. Based on this, optimizing logistics packaging cost control can have a significant effect on reducing total logistics costs. The improvement of packaging logistics technology can save logistics packaging raw materials to a large extent and reduce packaging material costs. And the technological improvements can also help save labor, promote logistics packaging efficiency, and reduce enterprise labor costs ${ }^{[2]}$. Improving logistics packaging technology can lower the threshold of packaging technology use and reduce the cost of enterprise technology to a certain extent. Together with energy - saving technology, it can reduce logistics energy consumption and lower energy costs. In addition, the strong guar- antee of packaging logistics technology can effectively control product loss, leading to relatively small compensation costs caused by logistics factors, thereby optimizing logistics costs ${ }^{[3]}$. Fifth, the effective application of packaging logistics technology can also reduce the working pressure of packaging equipment and minimize equipment losses, reducing the cost of logistics packaging machinery.

\section{Case analysis of packaging logistics tech-} nology and logistics cost optimization

\section{1 Research object}

Taking computers of brand $\mathrm{A}$ as the research object, their main customers are distributed in multiple regions worldwide, and their transportation methods are also relatively diverse. As is shown in Table 1 below.

Table 1 Annual Sales and Transportation Methods in Different Regions

\begin{tabular}{c|c|c|c|c|c|c}
\hline & Europe & $\begin{array}{c}\text { The Middle East } \\
\text { and Africa }\end{array}$ & Asia-Pacific & North America & Latin America & Total \\
\hline Annual sales & 750 & 150 & 250 & 350 & 250 & 1750 \\
\hline Air transportation & 350 & 100 & 150 & 250 & 100 & 100 \\
\hline Sea transportation & 350 & 50 & 50 & 50 & 0 & 650 \\
\hline Land transportation & 0 & 0 & 50 & 0 & 0 \\
\hline
\end{tabular}

In terms of product packaging, there are three mation, materials, and weight are shown in Table packaging design sizes, all using 1,200 $\mathrm{mm} \times 1$, 2 and Table 3 .

$000 \mathrm{~mm}$ standard pallets. Product packaging infor-

Table 2 Product Packaging Information Sheet

\begin{tabular}{c|c|c|c}
\hline Packing box & Percentage & Whole pallet & Number of whole pallets \\
\hline $\mathrm{C} 1(500 \times 100 \times 320)$ & $50 \%$ & $1200 \times 1000 \times 1100$ & 70 \\
\hline $\mathrm{C} 2(450 \times 160 \times 320)$ & $30 \%$ & $1200 \times 1000 \times 1100$ & 40 \\
\hline $\mathrm{C} 3(415 \times 260 \times 320)$ & $20 \%$ & $1200 \times 1000 \times 1100$ & 20 \\
\hline
\end{tabular}

Table 3 Product Packaging Materials and Weight

\begin{tabular}{c|c|c|c|c}
\hline Packaging & Material & C1 weight $(\mathrm{g})$ & C2 weight $(\mathrm{g})$ & C3 weight $(\mathrm{g})$ \\
\hline Packing box & Corrugated paper & 400 & 425 & 445 \\
\hline Accessory box & Corrugated paper & - & 315 & 300 \\
\hline Cushion & Corrugated paper & 210 & 210 & 210 \\
\hline Accessory partition & Corrugated paper & 45 & - & - \\
\hline Computer bag partition & Corrugated paper & - & - & 160 \\
\hline Document partition & Corrugated paper & 80 & - & - \\
\hline Machine bag & Polyethylene plastic & 10 & 10 & 10 \\
\hline
\end{tabular}

Calculate the transportation expenses based on different transportation methods and customer areas, and the basic information obtained is shown in Table 4.

Table 4 Transportation Expenses in Different Regions 


\begin{tabular}{c|c|c|c|c|c|c}
\hline & Europe & $\begin{array}{c}\text { The Middle East } \\
\text { and Africa }\end{array}$ & Asia-Pacific & North America & Latin America \\
\hline \multirow{2}{*}{ Air transportation } & 35 & 40 & 20 & 35 & 40 \\
\hline \multirow{3}{*}{ Sea transportation } & $20 \mathrm{C}$ & - & - & 12500 & - & - \\
\cline { 2 - 7 } & $40 \mathrm{C}$ & - & 27500 & - & - & 27500 \\
\hline & $40 \mathrm{HC}$ & 25000 & - & - & 25000 & - \\
\hline
\end{tabular}

\section{2 Material selection}

Half of the company's products are transported by air, and the weight of the products has a significant impact on the cost. To be more specific, if the weight of the product packaging can be reduced by $1 \mathrm{~g}$, more than RMB 400,000 in logistics cost can be saved each year. The company needs to se- lect packaging materials with outstanding portability and performance. The characteristics of the available packaging materials are analyzed, as shown in Table 5. Relatively speaking, choosing expandable polyethylene materials can get advantages such as lightness and cushion, which is more beneficial to the company's logistics cost savings.

Table 5 Analysis of Characteristics of Different Packaging Materials

\begin{tabular}{|c|c|c|c|}
\hline & Pulp & Expandable polyethylene & Recycled expandable polyethylene \\
\hline Cost/set ( RMB) & 3.5 & 3.85 & 4.0 \\
\hline Weight/set (g) & 210 & 85 & 85 \\
\hline Cushioning & General & Good & Good \\
\hline Appearance & Shavings, rougher & Good & General \\
\hline Processing & $\begin{array}{l}\text { Long cycle, poor deformation, } \\
\text { general shaping }\end{array}$ & $\begin{array}{c}\text { Long cycle, general shaping, } \\
\text { acceptable deformation }\end{array}$ & $\begin{array}{c}\text { Long cycle, general shaping, } \\
\text { acceptable deformation }\end{array}$ \\
\hline Environmental performance & $\begin{array}{l}\text { Partially decomposable; fully } \\
\text { recyclable; consume a lot of pulp }\end{array}$ & Recyclable; high cost & Environmental protection; high cost \\
\hline
\end{tabular}

\section{Summary and analysis of logistics cost con-} trol issues

\section{1 Loss due to the insufficient product packaging}

In actual work, the commodities are in the condition of inadequate packing because some logistics enterprises excessively save labor and materials and other related packaging costs out of the blind pursuit of economic benefits without scruples in the cost control of logistics packaging. In this case, the packaging cost of logistics enterprises seems to be saved to a certain extent, but the logistics commodity loss, in essence, cannot be ignored ${ }^{[4]}$. Blind saving leads to insufficient packaging, which will increase the loss of logistics products to a large extent. It will not only fail to optimize the logistics cost but will increase the logistics cost and will have a negative impact on the image and reputation of the logistics enterprises.

\section{2 Increased logistics costs due to excess packaging of commodities}

The opposite problem with insufficient packaging of commodities is excessive packaging. It refers to the excessive use of materials when packaging commodities, which leads to excessive packaging volume or complicated structural design and will also extend the packaging time ${ }^{[5]}$. Excess packaging can undoubtedly enable the commodities to be effectively protected in the circulation process. Still, it will lead to increased logistics costs and waste, which is unnecessary for the economic benefits of logistics enterprises and environmental protection.

\section{3 Insufficient consideration of ecological and envi- ronmental protection factors}

The impact of logistics packaging on the environment has become more and more significant with 
the development of the logistics industry. The random disposal of packaging materials and boxes, forming a huge amount of logistics waste, is not only a severe waste of resources but also a significant increase in environmental protection pressure [6]. The ecological and environmental protection problems caused by logistics waste will adversely affect the logistics industry, which is detrimental to the economic development of the logistics industry and the sustainable development of the social environment.

\section{Packaging logistics technology and logistics cost optimization measures}

\section{1 Strengthening the innovation of packaging de-} sign concepts and increasing the development and application of new technologies

In recent years, packaging waste has caused increasingly serious pollution to the natural environment and has an impact on the sustainable development of society and the economy. Whether packaging pollution can be effectively controlled and reduced, and the development of green packaging has gradually become the focus of attention of the public and related enterprises. In this context, attention should be paid to the development of design concepts, and environmental protection concepts and technologies shall be incorporated in the innovation and optimization of packaging logistics technology ${ }^{[7]}$. In packaging design, we should innovate based on environmental protection and energy - saving, reasonably reduce the packaging volume, reduce the energy consumption caused by logistics transportation and improve the utilization rate of logistics packaging on the basis of achieving the logistics effect. This can not only achieve logistics cost optimization but also meet the needs of environmental protection and energy - saving. In addition, logistics enterprises should strengthen their technological innovation and rationally integrate information technology and artificial intelligence into logistics packaging to improve efficiency and reduce costs.

\section{2 Reasonable selection of packaging materials and perfect stacking layout}

Reasonable selection of packaging materials is the first step of logistics packaging, and selecting suitable materials can play a significant role in optimizing logistics costs. First, it is necessary to use lightweight materials as much as possible. Because most of the current logistics cost calculations are based on weight. The application of lightweight materials can reduce the weight of packaging and reduce logistics costs. Second, pay attention to the protective properties of packaging materials, select materials with cushioning and good pressure resistance, and avoid selecting fragile and deformable materials for packaging ${ }^{[8]}$. Third, in recent years, the research and development of new green packaging materials have developed by leaps and bounds. In addition to packaging materials with specific functions, edible, recyclable, and biodegradable environmentally friendly packaging materials have been produced in large quantities and have gradually played an important role in many industries. In this context, it is also necessary to select recyclable and green materials for packaging [9]. In addition, improving the stacking layout based on commodities' attributes can increase the utilization rate of pallets, thereby reducing packaging and transportation costs ${ }^{[10]}$.

\section{3 Valuing social attributes of packaging, impro-} ving marketing and cost control

In recent years, the social attributes of packaging have received more and more attention. Therefore, reasonably improving the logistics attributes of packaging can also produce significant effects on product marketing and cost control. Analyze several cases concretely: Lepur uses the slogan "The world's first yogurt can be used to make friends with interesting foodies". The back of the yogurt packaging shell was made into a magazine that everyone can contribute to, attracting more than 2 , 000 people to participate. Twenty - five submissions were selected in the event and put on WeChat for everyone to vote, and then the voted content 
was used as new packaging, realizing the continuous update of product packaging. The enterprise also sets up a mysterious QR code on the lid of the Lepur box, through which the customer can get acquainted with another foodie with stories and can contact him/her immediately. In addition to Lepur yogurt, "let the packaging speak for you" and " help you express your love" of Weichuan Daily C, the "representative of young artists" and cartoon images of Jiang Xiao Bai, etc. , are all typical representative cases of the social attributes of packaging. This kind of packaging with social attributes can significantly close the relationship between products and consumers, strengthen interaction with consumers, and have certain reference value for product marketing and cost control.

\section{Conclusion}

Logistics cost control involves multiple links and multiple disciplines. Targeted technical and management optimization is the key to reducing logistics costs. As an important factor affecting logistics costs, packaging logistics technology still has excessive packaging, insufficient packaging, and insufficient environmental performance in practical applications. To optimize logistics cost by using packaging logistics technology, it is necessary for relevant units and personnel to strengthen the innovation of the packaging design concept, increase the development and application of new technology, and reasonably select packaging materials and improve the stacking layout. In addition, it is necessary to pay attention to the social attributes of packaging and improve marketing and cost control.

\section{References}

[1] Li Mengru, Li Dengming. Analysis and Control of Agricultural Cold Chain Logistics Cost from the Perspective of Poverty Alleviation and Assistance to Farmers [J]. Logistics Sci-Tech, 2020, 43 (07): $151-153$.

[2] Huang Shuai, Zhang Yilan. Logistics Packaging Technology Used in Mobile Phones in Circulation [J]. China Market, 2020(10):162-163+196.

[3] Guo Lijuan, Bi Xiaoqing. Research on the Recovery Cost of Express Packaging Waste under Circular Economy $[\mathrm{J}]$. Value Engineering, 2020, 39(02): 100 -101 .

[4] Zhang Tingting, Zhang Yi, Li Xinli. Buffer Packaging Design in the Transportation of Alcoholic Commodities Based on Modern Logistics Technology [J]. Liquor-Making Science \& Technology, 2020(05):118 -122 .

[5] Wang Rong. Analysis on Cost Control of Cold Chain Logistics of Agricultural Products in China [J]. Modern Marketing (Business Edition), 2020(01):182.

[6] Zhang Ting, Liao Jilin. An Empirical Study on the Evaluation and Control of Logistics Costs of HL Chain Supermarkets Based on AHP [J]. Logistics Engineering and Management, 2019, 41(10): 57-59.

[7] Gong Linling. Problems and countermeasures of cold chain logistics packaging of fresh agricultural products e- commerce $[J]$. Logistics Sci-Tech, 2019, 42 (10) : $66-67$.

[8] Zhou Yukai. Research on the Cost Accounting of Logistics Packaging Recovery in the Yangtze River Delta Area [J]. Modern Management Science, 2019 (06): $70-72$.

[9] Ye Lin. Impact of Food Packaging on Logistics Efficiency $[\mathrm{J}]$. The Food Industry, 2019, $40(05): 297-$ 301.

[10] Zhao Qing. Research on Packaging Logistics Technology and Logistics Cost Optimization [J]. China Logistics \& Purchasing, 2019(01):68. 